\title{
Correction: Chronic myeloid leukemia with insertion-derived $B C R-A B L 1$ fusion: redefining complex chromosomal abnormalities by correlation of FISH and karyotype predicts prognosis
}

Zhenya Tang 1 - Gokce A. Toruner · Guilin Tang · C. Cameron Yin · Wei Wang · Shimin Hu (D) B Beenu Thakral • Sa A. Wang · Roberto N. Miranda (D) J Joseph D. Khoury $(D \cdot$ L. Jeffrey Medeiros

Published online: 31 July 2020

(c) The Author(s), under exclusive licence to United States \& Canadian Academy of Pathology 2020

Correction to: Modern Pathology

https://doi.org/10.1038/s41379-020-0564-6

Author 'L. Jeffrey Medeiros' was listed in the original article as given name: 'L.', family name: 'Jeffrey
Medeiros'. However, this should be listed as given name: 'L. Jeffrey', family name: 'Medeiros'. This has been addressed by means of this correction article and updated in the original article. 